\title{
ADVANTAGES OF USING A ROBOTIC STAPLER IN RECTAL CANCER SURGERY
}

\author{
P. Tejedor ${ }^{1}$, F. Sagias ${ }^{1}$, D Nock ${ }^{1}$, K Flashman $^{1}$, N II Kandala ${ }^{2}$, JS Khan ${ }^{1}$.
}

1. Department of Colorectal Surgery, Queen Alexandra Hospital, Portsmouth, UK.

2. Faculty of Sciences, School of Health Sciences \& Social Work, University of Portsmouth, UK.

\section{Correspondence to:}

Jim S Khan.

Queen Alexandra Hospital, Portsmouth, UK.

Southwick Hill road Cosham, Portsmouth, PO6 3LY, UK

Tel 02392286000

Email: mkhan702@aol.com

Word count, body text: XXX words

Word count, abstract: XXX words

Figures: 3

Tables: 3

Disclosures: None

\section{AUTHOR'S CONTRIBUTION}

All authors critically revised the paper for important intellectual content. All authors have contributed to the work and agreed on the final version. This manuscript is not being considered by any other journal.

\section{KEY WORDS:}

Robotic stapler; Anastomotic leak; Robotic surgery; Total mesorectal excision; Rectal cancer; stapler firings. 


\begin{abstract}
To compare short-term postoperative outcomes in patients undergoing robotic total mesorectal excision (TME) after the use of robotic and laparoscopic staplers. Over a 5-year period, 196 patients were divided into 2 groups according to the use of laparoscopic (LS) or robotic stapler (RS). Patient demographics and postoperative complications were compared. A total of 145 (74\%) robotic TME were performed using the LS and $51(26 \%)$ the RS. No conversions to laparoscopy or laparotomy were observed, in either group. Transection of the rectum using one or two firings was achieved in a higher proportion of RS cases (91\%) compared with LS cases $(60 \% ; \mathrm{p}<0.001)$. The anastomotic leakage $(\mathrm{AL})$ rate was $4 \%$ in the RS group vs. $7 \%$ in the LS group $(\mathrm{p}>0.05)$. However, when three or more firings were needed for the rectal transection, the risk of $A L$ increased ( $3.4 \%$ with $\leq 2$ firings vs. $10.7 \%$ with $\geq 3$ firings, $p=0.006$ ). Our data confirm that multiple stapler firings for rectal transection have a major impact on AL. The robotic stapler simplifies the transaction, so that rectal division requires fewer stapler firings, with a potential reduction in the incidence of AL.
\end{abstract}




\section{INTRODUCTION}

Minimally invasive surgery for total mesorectal excision (TME) remains technically challenging, mostly because of poor manoeuvrability within the pelvis. The unfavourable entry angle makes it extremely difficult to introduce a laparoscopic linear stapler and transect the rectum low in the pelvis with only one or two firings. It has been demonstrated that three or more firings significantly increase the rate of anastomotic leakage (AL) (hazard ratio 7.8, 95\% confidence (CI) 3.8-16.3). ${ }^{1,2}$ Therefore, one of the most important technical and practical innovations of the robotic system is the use of the robotic stapler (EndoWrist Stapler, Intuitive Surgical, Inc.) (Fig. 1), which is introduced into the operative field by the assistant surgeon but is fully controlled by the surgeon. The stapler has a range of $108^{\circ}$ side-to-side articulation and $54^{\circ}$ up-and-down, enabling more precise positioning. Moreover, the stapler is capable of measuring tissue compression before and during stapler firing, making automatic adjustments. It then displays feedback to guide the surgeon towards $100 \%$ clamp completion. Only when the stapler is completely closed is the firing function enabled. The autonomy of the console surgeon on placement of the robotic stapler allows an easy antero-posterior placement of the stapler in the pelvis. With the increasing use of fluorescence (ICG) in the assessment of rectal perfusion, a robotic stapler allows a much accurate placement on a well-perfused bowel. This may have implications on the incidence of postoperative ischaemia and anastomotic leak.

With this systematic review and meta-analysis, we aimed to provide a comprehensive overview of the current data regarding safety of the robotic stapler, reporting on postoperative outcomes.

\section{METHODS}

A retrospective analysis was performed based on a prospectively maintained database. Patients eligible for inclusion included those with a rectal tumour at baseline considered to require complete TME who had undergone a robotic approach in a single centre over a 5-year period (May 2013 - May 2018). Patients were divided into two groups, based on the type of stapler employed to transect the rectum in the pelvis: LS or RS. Data recorded included patient demographics (sex, age, body mass index (BMI), American Society of Anesthesiologists (ASA) grade) and postoperative complications, including AL and reoperations. 


\section{Surgical technique}

All patients underwent robotic TME using single docking full robotic technique, ${ }^{3}$ divided into the following five modules. 1) Patient set-up: patient and robotic car set up, port placement, access and exposure, and docking; 2) Inferior mesenteric artery exposure and ligation, development of medial to lateral plane and inferior mesenteric vein division. 3) Left colonic and splenic flexure mobilisation, using an infracolic three-step approach. 4) Rectal dissection. 5) Rectal stapling, specimen extraction, anastomosis and closure. For the rectal transection, two types of staplers could be employed: LS - laparoscopic $45 \mathrm{~mm}$ stapler (Echelon FLEX ${ }^{\mathrm{TM}}$ Endopath ${ }^{\circledR}$, Ethicon), which is introduced trough the assistant trocar; RS robotic $45 \mathrm{~mm}$ stapler (EndoWrist Stapler, Intuitive Surgical), which is introduced trough a 12 $\mathrm{mm}$ robotic trocar, replacing the previous $8 \mathrm{~mm}$ trocar in $\mathrm{R} 1$, and which is fully controlled by the main surgeon at the console.

\section{Statistical analysis}

Descriptive statistics are presented, with mean and standard deviation (SD) or median and lower - upper quartiles (LQ, UP) for quantitative variables. Comparison of differences between groups was carried out using Chi-Squared analysis, with Fisher's exact test when any value observed in the contingency table was less than 5 . Differences between median values of the groups were assessed using Mann-Whitney $U$ test. Odds ratios (OR) were computed for dichotomous and continuous risk factors between groups and logistic regression was performed, selecting those variables that showed a $\mathrm{p}<0.25$ in the univariate analysis.

In the meta-analysis, continuous variables representing the postoperative outcomes were analyzed by the weighted mean difference (WMD). The Q test and $\mathrm{I}^{2}$ statistic were used to evaluate heterogeneity among studies. A Cochrane $\mathrm{Q}$ statistical $\mathrm{P}$ value $<0.10$ and/or $\mathrm{I}^{2}>$ $50 \%$ was taken to indicate significant heterogeneity. Publication bias was tested using funnel plots.

All statistical analyses were conducted using SPSS ${ }^{\circledR}$ version 22 software (SPSS, Inc., Chicago, IL) and $p$-values of $<0.05$ were considered statistically significant.

\section{RESULTS}

Over 5 years, 205 robotic TME were performed in our centre. Of these, nine patients were excluded from our analysis due to a lack of data; thus, 196 were included for further 
analysis. The demographic characteristics of each group are shown in Table 1. Most patients were male (70\%), with a median age of 69 (LQ, UQ: 61, 77) years. Median follow-up was 31 (LQ, UQ: 14, 47) months. A total of 145 (74\%) TME were performed using the LS and 51 $(26 \%)$ using the RS. The median operation time was similar between the two groups: 240 (LQ, UQ: 210, 290) minutes in the LS group vs. 250 (LQ, UQ: 140, 300) minutes in the RS group. The median length of hospital stay was 6 (LQ, UQ: 4, 9) days.

There were no conversions to laparoscopy or laparotomy. For both groups, the median number of firings required to transect the rectum was similar: 2 (LQ, UQ: 2, 3) in the LS vs. 2 (LQ, UQ: 2, 2) in the RS group. However, transection of the rectum using only 1 or 2 firings was achieved in just $60 \%$ of cases in the LS group compared to $91 \%$ in the RS group $(p<0.001)$. All remaining cases required three or more firings.

Major complications were lower in the RS group (Table 1). There was a difference in the primary endpoint, i.e. the rate of AL between the groups, which was $7 \%$ in the LS group vs. $4 \%$ in the RS group, which was not statistically significant ( $\mathrm{p}=0.735)$.

Results for the univariate and multivariable analysis, common factors that influenced AL are shown in Table 2. Results indicate that compared with less than 2 firings, when more than three firings were needed for the rectal transection, there is a $2.40 \%$ increased odds of $\mathrm{AL}$ and the results remains consistently higher $2.51 \%$ even after controlling for other variables. The difference however is not statistically significant.

\section{DISCUSSION}

The aim of this study was to investigate the impact of the RS on the rate of anastomotic leak. We have shown that it can be reduced by using the RS. In our experience, there were no significant differences in the median number of firings between the groups (two firings); however, it was possible to achieve complete rectal transection within two firings in $91 \%$ of cases with the robotic stapler, but only $60 \%$ of cases with the laparoscopic stapler $(p<0.0001)$. When three or more firings were needed to transect the rectum (which occurred in $40 \%$ of LS cases but only $9 \%$ of RS cases), the risk of AL increased, as shown in Table 2 . This was not statistically significant $(3.4 \%$ vs. $10.7 \%, p=0.06)$, probably due to the small sample size.

The laparoscopic rectal transection phase is a critical step due to the narrow space and the limited traction manipulation. The main advantage of the robotic stapler is undoubtedly its $90^{\circ}$ 
of articulation, which may provide more accurate firings in the confined space of the pelvis. Fewer stapler firings have been shown to translate to lower rates of AL, ${ }^{1,2}$ which was also noted in our study. Although not statistically significant, our data show a trend toward decreased AL for the RS group compared to the LS group (4\% vs. 7\%), which is probably due to the reduced number of firings required when using the RS.

There is a lack of data regarding postoperative outcomes after the use of the RS. Table 3 outlines key data published in previous studies and compares them with our study. Although results are not statistically significant, perhaps due due to the small number of AL in every studythe rate tends to decrease in all cases. To date, the RS has comparable outcomes to the $\mathrm{LS}^{4}$ but seems to require fewer firings for a rectal section $(\mathrm{p}<0.05) .{ }^{5,6}$ In our study, short-term outcomes and postoperative complications were also similar between the groups.

This is a retrospective, non-randomized study, so there are some inevitable biases. Our study is an observational study with a small sample size from a unique centre. As the majority of patients in the LS group were operated earlier, it could be a bias regarding the learning curve. However, the surgeons had already achieved proficiency in managing the stapler at the beginning of this study. A multicentre trial could be worthwhile to assess the safety of the robotic stapler and its role in reducing the rate of anastomotic leakage. Even so, we believe that despite the small sample size we have demonstrated the utility of this device in robotic rectal cancer surgery.

\section{CONCLUSIONS}

The use of the robotic stapler is safe and useful. It may help reducing the number of firings needed for rectal transactions and providing robotic surgeons with good control and autonomy for stapler firing.

Although the development of an anastomotic leak is multifactorial and unpredictable, our experience indicates that fewer stapler firings trend toward fewer leaks. Thus, the advantages of the robotic stapler in a narrow pelvis may lead in improved outcomes in robotic rectal cancer surgery. However, a randomised control trial or a large multicentre study is needed to confirm these findings. 


\section{COMPLIANCE WITH ETHICAL STANDARDS}

- No funding.

- Authors have no conflict of interest.

- All procedures performed in studies involving humans were in accordance with ethical standards of the institutional research committee and the 1964 Helsinki declaration and its later amendments.

- Informed consent was obtained from all participants. 


\section{TABLES}

Table 1. Patient characteristics.

\begin{tabular}{|c|c|c|c|}
\hline & $\begin{array}{c}\text { Laparoscopic } \\
\text { stapler } \\
\mathrm{n}=145\end{array}$ & $\begin{array}{l}\text { Robotic } \\
\text { stapler } \\
\mathrm{n}=51\end{array}$ & $\mathrm{p}$ value \\
\hline Age, median (LQ, UQ) (years) & $69(61,76)$ & $72(60,77)$ & 0.591 \\
\hline Sex, male:female $(\%)$ & $72: 28$ & $67: 33$ & 0.774 \\
\hline $\operatorname{BMI}\left(\mathrm{kg} / \mathrm{m}^{2}\right)$ & $27(24,29)$ & $26(23,29)$ & 0.172 \\
\hline \multicolumn{4}{|l|}{ ASA } \\
\hline $\mathrm{I}$ & $9 \%$ & $16 \%$ & \\
\hline II & $72 \%$ & $65 \%$ & 0.216 \\
\hline III & $17 \%$ & $12 \%$ & \\
\hline IV & $2 \%$ & $7 \%$ & \\
\hline \multicolumn{4}{|l|}{ Firings } \\
\hline$\leq 2$ & $60 \%$ & $91 \%$ & $<0.001$ \\
\hline$\geq 3$ & $40 \%$ & $9 \%$ & \\
\hline $\begin{array}{l}\text { Total operative time, mean (SD) } \\
(\mathrm{min})\end{array}$ & $247(81)$ & $284(96)$ & 0.017 \\
\hline $\mathrm{AL}(\mathrm{n}, \%)$ & $10(7)$ & $2(4)$ & 0.735 \\
\hline Radiological leak (\%) & 6.3 & 2 & 0.540 \\
\hline Reoperation due to AL (\%) & 0.7 & 2 & 0.454 \\
\hline LOS, median (LQ, UQ), days & $6(5)$ & $6(6)$ & 0.450 \\
\hline 30-day readmission & $12(8)$ & $6(12)$ & 0.277 \\
\hline $\begin{array}{l}\text { Follow-up, in months } \\
\text { (median, LQ, UQ) }\end{array}$ & $36(27,52)$ & $9.5(5,14)$ & $<0.0001$ \\
\hline
\end{tabular}

AL, anastomotic leak; ASA, American Society of Anesthesiologists grade; BMI, body mass index; LQ, lower quartile, UQ, upper quartile; LOS, length of hospital stay; P-values in bold means Statistically significant 
Table 2. Univariate and multivariate analysis of risk factors for anastomotic leakage (AL) in all patients $(\mathrm{n}=196)$

\begin{tabular}{|c|c|c|c|c|c|c|c|}
\hline \multirow[b]{2}{*}{ Variable } & \multirow{2}{*}{$\begin{array}{c}\text { Anastomotic } \\
\text { leakage } \\
\text { n }(\%)\end{array}$} & \multicolumn{3}{|c|}{ Univariate analysis } & \multicolumn{3}{|c|}{ Multivariable analysis } \\
\hline & & OR & $95 \% \mathrm{CI}$ & $\begin{array}{c}\mathrm{p}- \\
\text { value }\end{array}$ & OR & $95 \% \mathrm{CI}$ & $\begin{array}{c}\mathrm{p}- \\
\text { value }\end{array}$ \\
\hline Stapler & & & & 0.452 & & & 0.996 \\
\hline $\mathrm{LS}$ & $10(6.9)$ & 1.00 & & & 1.00 & & \\
\hline $\mathrm{RS}$ & $2(3.9)$ & 1.82 & $0.38-8.58$ & & 1.01 & $0.08-12.06$ & \\
\hline Firings & & & & & & & 0.200 \\
\hline$\leq 2$ & $4(3.4)$ & 1.00 & & 0.067 & 1.00 & & \\
\hline$\geq 3$ & $6(10.7)$ & 3.39 & $0.92-12.54$ & & 3.51 & $0.52-23.85$ & \\
\hline Age in years & & & & 0.230 & & & 0.857 \\
\hline$<75$ & $11(7.7)$ & 1.00 & & & 1.00 & & \\
\hline$\geq 75$ & $2(3.2)$ & 0.39 & $0.08-1.82$ & & 0.85 & $0.15-4.75$ & \\
\hline Sex & & & & 0.107 & & & 0.998 \\
\hline Female & $1(1.6)$ & 1.00 & & & 1.00 & & \\
\hline Male & $12(8.3)$ & 0.18 & $0.02-1.44$ & & 0.00 & $0.00-0.00$ & \\
\hline BMI & & & & 0.745 & & & 0.543 \\
\hline$<30$ & $9(6.1)$ & 1.00 & & & 1.00 & & \\
\hline$\geq 30$ & $3(7.5)$ & 1.25 & $0.32-4.86$ & & 1.63 & $0.34-7.81$ & \\
\hline ASA & & & & 0.987 & & & 0.928 \\
\hline$<$ III & $9(5.7)$ & 1.00 & & & 1.00 & & \\
\hline$\geq \mathrm{III}$ & $3(10)$ & 0.99 & $0.21-4.73$ & & 1.09 & $0.18-6.53$ & \\
\hline $\begin{array}{l}\text { Preoperative } \\
\text { radiotherapy }\end{array}$ & & & & 0.338 & & & 0.532 \\
\hline Yes & $4(9.8)$ & 1.00 & & & 1.00 & & \\
\hline No & $9(5.6)$ & 1.83 & $0.53-6.26$ & & 4.30 & $0.04-416.74$ & \\
\hline $\begin{array}{l}\text { Preoperative } \\
\text { chemotherapy }\end{array}$ & & & & 0.542 & & & 0.680 \\
\hline Yes & $4(8.3)$ & 1.00 & & & 1.00 & & \\
\hline No & $9(5.8)$ & 1.47 & $0.43-4.98$ & & 0.38 & $0.01-37.84$ & \\
\hline
\end{tabular}

ASA, American Society of Anesthesiologists; BMI, body mass index; CI, confidence interval; OR, odds ratio. 


\section{FIGURE LEGENDS}

Fig. 1. The da Vinci ${ }^{\circledR}$ robotic stapler (EndoWrist Stapler, Intuitive Surgical, Inc.).

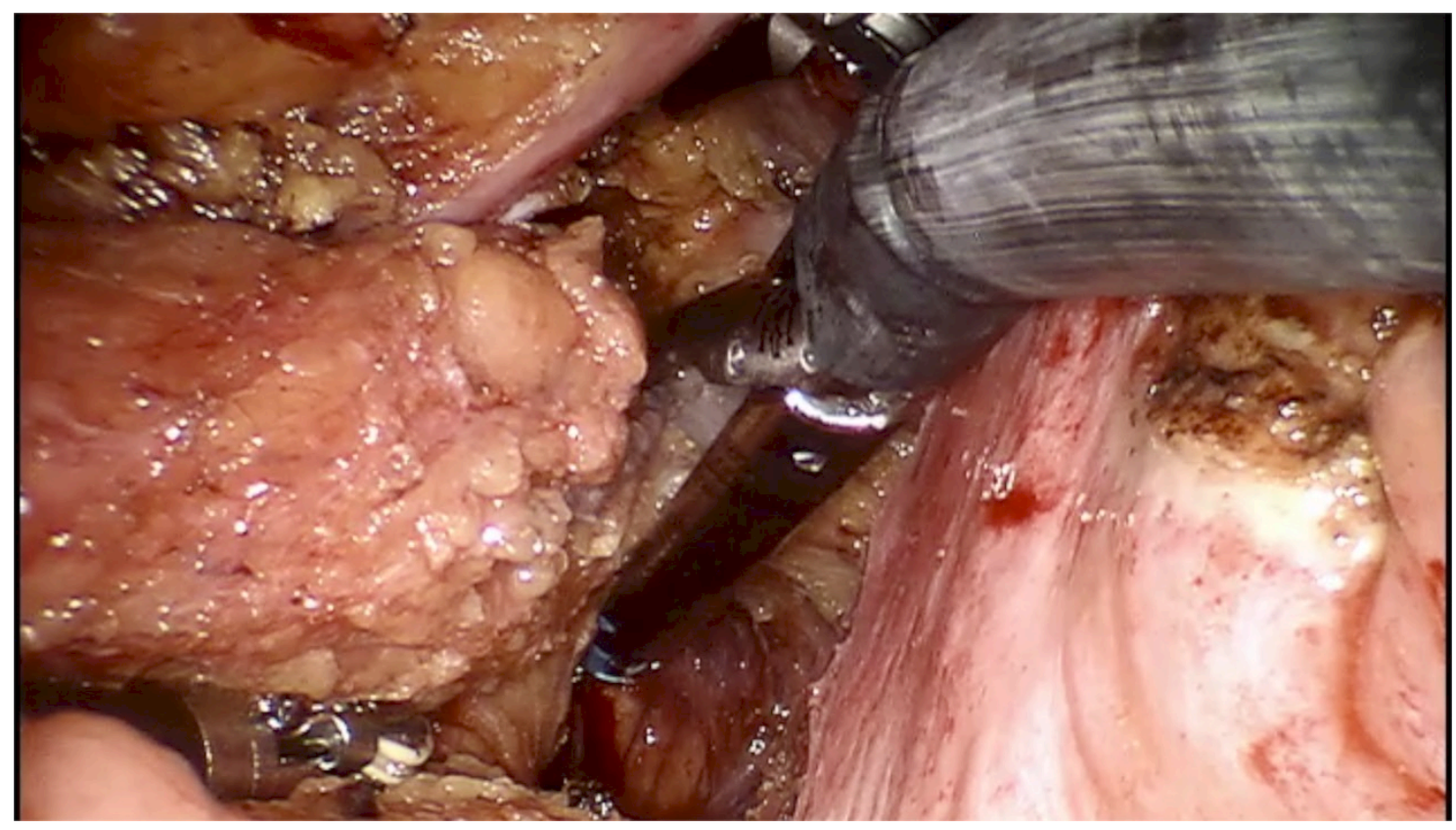




\section{REFERENCES}

Park JS, Choi GS, Kim SH, Kim HR, Kim NK, Lee KY, Kang SB, Kim JY, Lee KY, Kim BC, Bae BN, Son GM, Lee SI, Kang H (2013) Multicenter analysis of risk factors for anastomotic leakage after laparoscopic rectal cancer excision: the Korean laparoscopic colorectal surgery study group. Ann Surg 257(4):665-671.

https://doi.org/10.1097/SLA.0b013e31827b8ed9

CrossRefPubMedGoogle Scholar

2.

Braunschmid T, Hartig N, Baumann L, Dauser B, Herbst F (2017) Influence of multiple stapler firings used for rectal division on colorectal anastomotic leak rate. Surg Endosc 31(12):5318-5326. https://doi.org/10.1007/s00464-017-5611-0

CrossRefPubMedPubMedCentralGoogle Scholar

3.

Johnson CS, Kassir A, Marx DS, Soliman MK (2019) Performance of da Vinci Stapler during robotic-assisted right colectomy with intracorporeal anastomosis. J Robot Surg 13(1):115-119. https://doi.org/10.1007/s11701-018-0828-z

CrossRefPubMedGoogle Scholar

4 .

Ahmed J, Siddiqi N, Khan L, Kuzu A, Parvaiz A (2016) Standardized technique for singledocking robotic rectal surgery. Colorect Dis 18(10):0380-0384.

https://doi.org/10.1111/codi.13466

CrossRefGoogle Scholar

5.

Hosmer DWLS (2000) Applied logistic regression. University of Massachusetts, Massachusetts

CrossRefGoogle Scholar

6.

Holzmacher JL, Luka S, Aziz M, Amdur RL, Agarwal S, Obias V (2017) The use of robotic and laparoscopic surgical stapling devices during minimally invasive colon and rectal surgery: a comparison. J Laparoendosc Adv Surg Tech Part A 27(2):151-155.

https://doi.org/10.1089/lap.2016.0409

CrossRefGoogle Scholar 
7.

group TESoCEc (2018) An international multicentre prospective audit of elective rectal cancer surgery; operative approach versus outcome, including transanal total mesorectal excision (TaTME). Colorect Dis 20(Suppl 6):33-46.

https://doi.org/10.1111/codi.14376

CrossRefGoogle Scholar

8.

Jayne D, Pigazzi A, Marshall H, Croft J, Corrigan N, Copeland J, Quirke P, West N, Rautio T, Thomassen N, Tilney H, Gudgeon M, Bianchi PP, Edlin R, Hulme C, Brown J (2017) Effect of robotic-assisted vs conventional laparoscopic surgery on risk of conversion to open laparotomy among patients undergoing resection for rectal cancer: the ROLARR randomized clinical trial. JAMA 318(16):1569-1580.

https://doi.org/10.1001/jama.2017.7219

CrossRefPubMedPubMedCentralGoogle Scholar

9.

Baik SH, Kwon HY, Kim JS, Hur H, Sohn SK, Cho CH, Kim H (2009) Robotic versus laparoscopic low anterior resection of rectal cancer: short-term outcome of a prospective comparative study. Ann Surg Oncol 16(6):1480-1487.

https://doi.org/10.1245/s10434-009-0435-3

CrossRefPubMedGoogle Scholar

10.

Kang J, Yoon KJ, Min BS, Hur H, Baik SH, Kim NK, Lee KY (2013) The impact of robotic surgery for mid and low rectal cancer: a case-matched analysis of a 3-arm comparisonopen, laparoscopic, and robotic surgery. Ann Surg 257(1):95-101.

https://doi.org/10.1097/SLA.0b013e3182686bbd

CrossRefPubMedGoogle Scholar

11.

Lee SH, Kim DH, Lim SW (2018) Robotic versus laparoscopic intersphincteric resection for low rectal cancer: a systematic review and meta-analysis. Int J Colorectal Dis 33(12):1741-1753. https://doi.org/10.1007/s00384-018-3145-0

CrossRefPubMedGoogle Scholar

12. 
Baek JH, McKenzie S, Garcia-Aguilar J, Pigazzi A (2010) Oncologic outcomes of roboticassisted total mesorectal excision for the treatment of rectal cancer. Ann Surg 251(5):882-886. https://doi.org/10.1097/SLA.0b013e3181c79114 CrossRefPubMedGoogle Scholar

13.

Atasoy D, Aytac E, Ozben V, Bayraktar O, Erenler Bayraktar I, Aghayeva A, Baca B, Hamzaoglu I, Karahasanoglu T (2018) Robotic versus laparoscopic stapler use for rectal transection in robotic surgery for cancer. J Laparoendosc Adv Surg Tech Part A 28(5):501-505. https://doi.org/10.1089/lap.2017.0545

CrossRefGoogle Scholar

14.

Guadagni S, Di Franco G, Gianardi D, Palmeri M, Ceccarelli C, Bianchini M, Furbetta N, Caprili G, D'Isidoro C, Moglia A, Melfi F, Buccianti P, Mosca F, Morelli L (2018) Control comparison of the new EndoWrist and traditional laparoscopic staplers for anterior rectal resection with the Da Vinci Xi: a case study. J Laparoendosc Adv Surg Tech Part A 28(12):1422-1427. https://doi.org/10.1089/lap.2018.0218 CrossRefGoogle Scholar 